\title{
Developmental distribution of the plasma membrane-enriched proteome in the maize primary root growth zone
}

\author{
Zhe Zhang ${ }^{1,2,3 t \ddagger}$, Priyamvada Voothuluru ${ }^{3,4 \neq}$, Mineo Yamaguchi ${ }^{3,4}$, Robert E. Sharp ${ }^{3,4}$ and Scott C. Peck ${ }^{1,2,3 *}$ \\ ${ }^{1}$ Division of Biochemistry, University of Missouri, Columbia, MO, USA \\ ${ }^{2}$ Christopher S. Bond Life Sciences Center, University of Missouri, Columbia, MO, USA \\ ${ }^{3}$ Interdisciplinary Plant Group, University of Missouri, Columbia, MO, USA \\ ${ }^{4}$ Division of Plant Sciences, University of Missouri, Columbia, MO, USA
}

\section{Edited by:}

Harvey Millar, The University of

Western Australia, Australia

\section{Reviewed by:}

Berit Ebert, Lawrence Berkeley Lab Joint BioEnergy Institute, USA

Ning LI, The Hong Kong University of Science and Technology, China

\section{*Correspondence:}

Scott C. Peck, Department of Biochemistry, Christopher S. Bond Life Science Center, University of Missouri, 271H Bond Life Sciences Center, 1201 Rollins Street, Columbia M065211, USA.

e-mail: pecks@missouri.edu

\section{${ }^{\dagger}$ Present address:}

Zhe Zhang, Department of Hematology, Mayo Clinic, Rochester, MN, USA.

${ }^{\ddagger}$ Zhe Zhang and Priyamvada Voothuluru have contributed equally to this work.
Within the growth zone of the maize primary root, there are well-defined patterns of spatial and temporal organization of cell division and elongation. However, the processes underlying this organization remain poorly understood. To gain additional insights into the differences amongst the defined regions, we performed a proteomic analysis focusing on fractions enriched for plasma membrane (PM) proteins. The PM is the interface between the plant cell and the apoplast and/or extracellular space. As such, it is a key structure involved in the exchange of nutrients and other molecules as well as in the integration of signals that regulate growth and development. Despite the important functions of PM-localized proteins in mediating these processes, a full understanding of dynamic changes in PM proteomes is often impeded by low relative concentrations relative to total proteins. Using a relatively simple strategy of treating microsomal fractions with Brij-58 detergent to enrich for PM proteins, we compared the developmental distribution of proteins within the root growth zone which revealed a number of previously known as well as novel proteins with interesting patterns of abundance. For instance, the quantitative proteomic analysis detected a gradient of PM aquaporin proteins similar to that previously reported using immunoblot analyses, confirming the veracity of this strategy. Cellulose synthases increased in abundance with increasing distance from the root apex, consistent with expected locations of cell wall deposition. The similar distribution pattern for Brittlestalk-2-like protein implicates that this protein may also have cell wall related functions. These results show that the simplified PM enrichment method previously demonstrated in Arabidopsis can be successfully applied to completely unrelated plant tissues and provide insights into differences in the PM proteome throughout growth and development zones of the maize primary root.

Keywords: plasma membrane, proteomics, growth zone, maize, roots, development

\section{INTRODUCTION}

Unlike animals, plants continue to grow and increase in size throughout their lifecycle. Plant growth, however, does not occur indiscriminately but rather is distributed through defined regions of roots and shoots that are referred to as the growth zones (Erickson and Silk, 1979). Within these regions of growth, there is considerable variability in spatial and temporal cell production and cell elongation, two processes defining the overall growth rate (Peters and Bernstein, 1997; Beemster and Baskin, 1998). Therefore, these growth zones have been used extensively to study the processes contributing to cell production and elongation (Pilet et al., 1983; MacAdam et al., 1992; Bernstein et al., 1993; Liang et al., 1997).

Among plant organs, the root has a relatively simple organization of the growth zone, making it a good model for studying various aspects of plant growth (Beemster and Baskin, 1998; Sharp et al., 2004; Brady et al., 2005). The meristematic region with dividing cells is near the tip of the root, and the elongation region consisting of cells at various stages of expansion progresses away from the zone of division. Cell elongation accelerates as cells move out of the meristem, reaching a maximal rate in the middle of the growth zone, and decelerates thereafter such that cells reach their final length by the end of the growth zone. This spatial distribution of cell production and cell elongation has been exploited for numerous studies of growth related processes, revealing gradients within these zones of metabolites, phytohormones, $\mathrm{pH}$, transcription factor proteins, and cell wall-modifying proteins (Mulkey and Evans, 1980; Pilet et al., 1983; Sharp et al., 1990; Baskin et al., 2004; Brady et al., 2005; Wolters and Jurgens, 2009; Yamaguchi and Sharp, 2010).

Because the plasma membrane (PM) is the interface between a cell and the apoplast/environment, it is a key structure involved in integrating signals and responses involved in cell growth. For instance, PM-localized proteins such as ion and water channels are 
necessary for regulating turgor and cell elongation in roots (Kiegle et al., 2000; Hachez et al., 2006). The acidification of apoplastic $\mathrm{pH}$ by the PM-localized proton ATPase has been shown to be important for wall loosening and cell elongation in different plant species (Pilet et al., 1983; Cosgrove, 1989). Additionally, cells at various stages of elongation must constantly modify their cell walls, and several metabolites needed for cell wall deposition are transported across the PM (Wightman and Turner, 2010; Endler and Persson, 2011).

Despite the important functions of PM proteins in the regulation of growth, these proteins are often underrepresented in proteomic analyses because they are found in low concentrations relative to the total cellular protein content (Ephritikhine et al., 2004; Morel et al., 2006; Zhang and Peck, 2011). To increase depth of coverage, aqueous two-phase partitioning is often utilized which, although ideal for yielding highly purified PM fractions, is both time-consuming and technically challenging, often requiring significant technical optimization for each new tissue or species examined (Albertsson et al., 1987; Komatsu, 2008). Although crude microsomal fractionation does enrich for PM proteins over total protein, the large degree of contamination from other organellar proteins, particularly from the endoplasmic reticulum (ER), still limits the depth of coverage of PM proteomes. Using Arabidopsis suspension cell cultures as starting material, Zhang and Peck (2011) recently reported a simple method for decreasing the representation of organellar proteins from crude microsomal fractions to obtain greater than threefold enrichment of PM proteins from Arabidopsis culture cells for proteomic analyses while decreasing contamination with ER proteins by sevenfold. Although this method is not applicable to assigning definitive location of a protein to the PM because it does not yield samples as pure as those from aqueous two-phase partitioning, the strategy is useful to enrich sufficiently for the PM fraction to allow for meaningful quantitative comparisons. In the current study, we evaluated the applicability of this simplified PM enrichment method using the growth zone of maize primary roots grown under well-watered conditions. We demonstrate that the strategy is easily transferred to this new tissue and species, and we report the region-specific distribution of proteins, including many PM proteins, associated with the spatial growth pattern.

\section{MATERIALS AND METHODS CHEMICALS}

All chemicals used in this study were ultrapure grade (obtained from Sigma-Aldrich Co, St. Louis, MO, USA; Fisher Scientific, Pittsburgh, PA, USA; Promega Corp., Madison, WI, USA). HPLCwater was obtained from the Millipore Synthesis system (Millipore Corp. Billerica, MA, USA).

\section{PLANT GROWTH AND TISSUE COLLECTION}

B73 X MO17 hybrid maize seed were used in all experiments. Seeds were surface sterilized in $5 \% \mathrm{NaClO}$ solution for $15 \mathrm{~min}$, rinsed with deionized water for $15 \mathrm{~min}$, and imbibed in aerated $1 \mathrm{mM} \mathrm{CaSO}_{4}$ solution for $24 \mathrm{~h}$. The imbibed seeds were germinated between sheets of germination paper moistened with $1 \mathrm{mM}$ $\mathrm{CaSO}_{4}$ solution at $29^{\circ} \mathrm{C}$ and near-saturating humidity in the dark.
Seedlings with primary roots of $10-20 \mathrm{~mm}$ in length were transplanted against the interior surface of Plexiglass containers filled with vermiculite (no. 2A, Therm-O-Rock East Inc., New Eagle, PA, USA) which was moistened to the drip point with $1 \mathrm{mM}$ $\mathrm{CaSO}_{4}$ solution. The seedlings were then grown at $29^{\circ} \mathrm{C}$ and nearsaturating humidity in the dark for $48 \mathrm{~h}$. Primary root elongation was monitored by periodically marking the position of the root apices on the Plexiglass. The apical $20 \mathrm{~mm}$ of the primary roots were harvested and divided into four regions (all distances are from the root apex including the root cap); the $0-3 \mathrm{~mm}$ region (R1), the $3-7 \mathrm{~mm}$ region ( $\mathrm{R} 2)$, the $7-12 \mathrm{~mm}$ region ( $\mathrm{R} 3$ ), and the $12-20 \mathrm{~mm}$ region (R4) (Figure 1A). The harvested root segments were collected by position, transferred to tubes containing liquid nitrogen, and stored at $-80^{\circ} \mathrm{C}$. In each of three replicate experiments, root segments were harvested from $>150$ seedlings for proteomic analysis. Transplanting, root elongation measurements, and harvesting were performed using a green "safe" light (Saab et al., 1990).

\section{KINEMATIC ANALYSIS OF DISPLACEMENT VELOCITY AND RELATIVE ELONGATION RATE PROFILES}

The spatial distributions of displacement velocity and relative elongation rate in the primary root growth zone were obtained from cell length profiles and root elongation rates as described by Silk et al. (1989). Briefly, 10 seedlings were grown for $48 \mathrm{~h}$ and their root elongation monitored periodically. Elongation rates were steady after $\sim 15 \mathrm{~h}$ from transplanting as required for accurate determinations of elongation rate profiles from anatomical records. Three to four roots that were straight and had an elongation rate similar to the mean of the population were then harvested for cell length measurements. The apical $15 \mathrm{~mm}$ was sectioned longitudinally using a vibratome (Lancer series 1000 Vibratome, St Louis, MO, USA) and a $125 \mu \mathrm{m}$ thick section of each root was stained with $1 \mathrm{mg} \mathrm{mL} \mathrm{mL}^{-1}$ of Calcofluor (Sigma-Aldrich, St. Louis, MO, USA) for $15 \mathrm{~min}$ to visualize the cell walls. The stained sections were imaged by confocal microscopy as described by Yamaguchi et al. (2010). Average cell lengths at various positions from the root apex were calculated by measuring the cell lengths of 4-12 cortical cells. The final cell lengths were calculated by averaging the four most distal measurement positions (12-15 mm from the root apex). Displacement velocities were calculated using the relationship $L_{\mathrm{A}} / L_{\mathrm{F}}=V_{\mathrm{A}} / V_{\mathrm{F}}$, as described in Silk et al. (1989) where

$L_{\mathrm{A}}=$ the mean cell length at position A

$L_{\mathrm{F}}=$ final cell length

$V_{\mathrm{A}}=$ displacement velocity at position $\mathrm{A}$

$V_{\mathrm{F}}=$ the final displacement velocity (equal to the root elongation rate).

The cell length method cannot be used to calculate accurate displacement velocities in the meristematic region (Silk et al., 1989). Therefore, displacement velocities were calculated starting at the distal end of the meristem, which was estimated to occur at a cell length of 2.5 times the length of the shortest cells $(2.5 \mathrm{~mm}$ from the root apex; Erickson, 1961). The mean displacement velocities were plotted and a fifth-order polynomial curve was fitted to the 

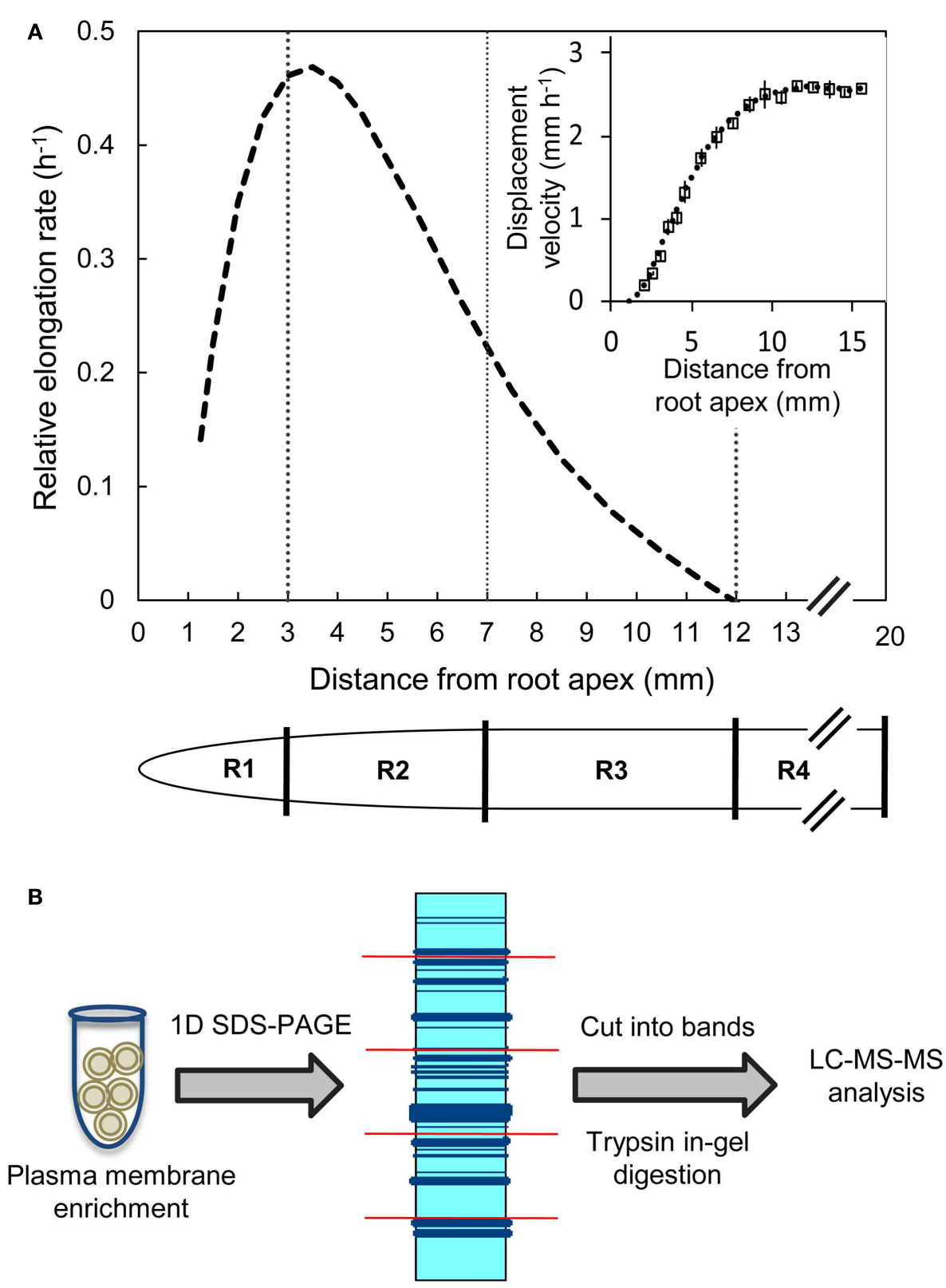

FIGURE 1 | (A) Relative elongation rate profile and displacement velocity profile (inset) as a function of distance from the root apex (including the root cap) of the primary root of maize hybrid line B73 X M017 grown under well-watered conditions. The spatial distribution of displacement velocity $\left(\mathrm{mm} \mathrm{h}^{-1}\right)$ from the root apex was calculated from root elongation rate and cell length profile data obtained at $48 \mathrm{~h}$ after transplanting (data are means $\pm S E, n=3$ ). A fifth-order polynomial curve was fitted to the displacement velocity profile and the derivative of displacement velocity against position was used to obtain the relative elongation rate profile $\left(\mathrm{h}^{-1}\right)$. Tissues from region $1(\mathrm{R} 1,0-3 \mathrm{~mm})$, region $2(\mathrm{R} 2,3-7 \mathrm{~mm})$, region $3(\mathrm{R} 3,7-12 \mathrm{~mm})$, and region $4(\mathrm{R} 4,12-20 \mathrm{~mm})$ were harvested. (B) Label-free proteomics work flow shown for plasma membrane-enriched samples as protein input followed by in-gel tryptic digestion and LC-MS/MS analysis. data (Figure 1A inset). The derivative of the resulting curve was used to obtain the relative elongation rate profile (Figure 1A; Silk et al., 1989).

PROTEIN EXTRACTION AND PLASMA MEMBRANE ENRICHMENT

Frozen root tissues were ground to a fine powder and proteins were extracted as described by Zhang and Peck (2011). Briefly, proteins were extracted from the tissues using $1 \mathrm{~mL}$ of ice-cold buffer $\mathrm{H}$ (330 mM sucrose, $50 \mathrm{mM}$ HEPES/KOH pH 7.5, $50 \mathrm{~mm}$ $\mathrm{Na}_{4} \mathrm{P}_{2} \mathrm{O}_{7}, 25 \mathrm{~mm} \mathrm{NaF}, 5 \%$ glycerol, $0.5 \%$ polyvinyl pyrrolidone, $10 \mathrm{~mm}$ EDTA, $1 \mathrm{mM} \mathrm{Na} \mathrm{MoO}_{4}, 1 \mathrm{mM}$ PMSF, $10 \mathrm{mM}$ leupeptin A, $1 \mathrm{nM}$ calyculin A, and $3 \mathrm{mM}$ DTT) per gram fresh weight of tissue. The samples were subsequently centrifuged for $10 \mathrm{~min}$ $\left(10,000 \times g\right.$ at $\left.4^{\circ} \mathrm{C}\right)$ to remove cell debris. The supernatant was 
used to obtain crude microsomal pellets by ultracentrifugation for $30 \mathrm{~min}\left(100,000 \times \mathrm{g}\right.$ at $\left.4^{\circ} \mathrm{C}\right)$. The microsomal pellets were washed with buffer $\mathrm{H}$ without DTT, incubated in $2 \mu \mathrm{L}$ of buffer B (buffer $\mathrm{H}$ without DTT but with $0.02 \% \mathrm{w} / \mathrm{v}$ Brij-58) per $\mu \mathrm{g}$ of crude microsomal protein on ice for $45 \mathrm{~min}$ and centrifuged for $30 \mathrm{~min}$ at $100,000 \times \mathrm{g}$. The resulting pellets were washed with $10 \mathrm{mM} \mathrm{Na}_{2} \mathrm{CO}_{3}$ (pH 11-12) in buffer $\mathrm{H}$ without DTT to yield the $\mathrm{PM}$-enriched protein fraction.

\section{IMMUNOBLOTTING}

Protein samples from the soluble fraction, crude microsomes, and PM-enriched fraction were separated by SDS-PAGE and transferred to Immobilon $\mathrm{P}$ membrane for $2 \mathrm{~h}$ at $70 \mathrm{~V}$ in Towbin's transfer buffer ( $39 \mathrm{mM}$ glycine, $48 \mathrm{mM}$ Tris-base, $0.037 \%$ SDS, and $20 \%$ methanol) at $4{ }^{\circ} \mathrm{C}$. The membranes were incubated first in blocking buffer (Tris-buffered saline at $\mathrm{pH} 7.8$ containing 5\% non-fat milk and $0.05 \%$ Tween-20) for $1 \mathrm{~h}$ at room temperature, then incubated with primary antibodies in blocking buffer at $4^{\circ} \mathrm{C}$ overnight, and finally incubated in blocking buffer containing the secondary antibody horseradish peroxidase-labeled anti-rabbit IgG (Sigma-Aldrich Co, St. Louis, MO, USA) for $1 \mathrm{~h}$ at room temperature. Supersignal Femto or Pico substrate (Thermo Scientific, IL, USA) was used for chemiluminescence detection. The primary antibodies (antibodies were obtained from Agrisera, Sweden) used in the study were $\alpha$-AHA $\left(\mathrm{H}^{+}\right.$-ATPase, PM marker) and $\alpha$-SMT-1 (sterol methyltransferase-1, ER marker).

\section{SDS-PAGE ANALYSIS AND TRYPTIC DIGESTION}

For each biological replicate, equal concentrations $(\sim 30 \mu \mathrm{g})$ of PM-enriched protein from each region of the growth zone were solubilized in sample loading buffer, heated to $75^{\circ} \mathrm{C}$, separated by $8 \%$ SDS-PAGE and stained with colloidal Coomassie G-250 overnight, as described by Neuhoff et al. (1985). The following day, gels were destained in distilled water, and each gel lane was cut into eight slices with a razor blade. The proteins from the gel slices were reduced with $50 \mathrm{mM}$ TCEP-HCl, alkylated with $50 \mathrm{mM}$ iodoacetamide and digested within the gel overnight using 1:20 w/w trypsin in $100 \mathrm{mM}$ ammonium bicarbonate buffer $(\mathrm{pH} 8.3)$ at $37^{\circ} \mathrm{C}$. After digestion, the peptides were eluted twice with $1 \%$ trifluoroacetic acid with $60 \%$ acetonitrile, and the eluted mixture was lyophilized overnight to obtain dried peptides. The dry peptides were stored at $-80^{\circ} \mathrm{C}$ until LC-MS/MS analysis.

\section{LC-MS/MS ANALYSIS}

Lyophilized peptides dissolved in $0.1 \%$ formic acid were applied to a $10 \mathrm{~cm}$ prepacked column (Picotips with $75 \mu \mathrm{m}$ inner diameter and $15 \mu \mathrm{m}$ tip, obtained from New Objective, Woburn, MA, USA) and eluted into the nanoelectrospray ion source of a LTQ-Orbitrap LC-MS/MS mass spectrometer (Thermoelectron Corp., Rockford, IL, USA) that was controlled by XCalibur version 2.2.1. The mass spectrometer operating in data-dependent mode was used to carry out a fully automated chromatography run using $1 \%$ formic acid and $99.9 \%$ acetonitrile, $0.1 \%$ formic acid with a $1 \%$ per min incremental gradient for the first $45 \mathrm{~min}$ and $11 \%$ per min for the final $5 \mathrm{~min}$. The mass spectrometer measurements were obtained with the specifications as described in Zhang and Peck (2011).

\section{PEPTIDE AND PROTEIN IDENTIFICATION}

Mascot Distiller version 2.0 (Matrix Science, London, UK) was used to deconvolute the tandem mass spectra. However, deisotoping was not performed. Mascot (server version 2.3, Matrix Science, London, UK) and X! Tandem (version 2007.01.01.1) ${ }^{1}$ were used to analyze the MS/MS spectra by searching an inhouse database created by downloading all Zea mays proteins from $\mathrm{NCBI}^{2}$ and filtering for duplicate entries. The MS/MS based peptide and protein identities were validated by Scaffold (version Scaffold_3_00_08, Proteome Software Inc., Portland, OR, USA). The specified variable modifications were oxidized methionine and iodoacetamide derivative of cysteine. The identities of peptides (at greater than 95\% probability) were accepted using the Peptide Prophet algorithm (Keller et al., 2002), and identities of proteins with at least two peptides identified (at greater than $99 \%$ probability) were accepted using the Protein Prophet algorithm (Nesvizhskii et al., 2003), respectively. If proteins containing similar peptides could not be differentiated based on MS/MS analysis alone, they were grouped to satisfy the principles of parsimony.

\section{DATA ANALYSIS AND BIOINFORMATICS}

Spectral counts were normalized within a biological replicate using the mean of total spectral counts from all four regions (the average deviation within an experiment was $\sim 3 \%$ ). For each region, the mean and standard deviation were calculated using the spectral counts from all three biological experiments. Proteins for which the fold difference between the means was greater than the two times the coefficient of variation (CV) determined for a technical replicate determined using these samples $(\mathrm{CV}=0.34)$ was considered for pattern analysis.

To assign the distribution of proteins within the different regions, the protein data were analyzed according to the following steps. Proteins identified in at least two out of the three biological replicates within a region were considered reproducible. Reproducible proteins were used to generate a four-way Venn diagram (Figure 2C) using the algorithm at http://bioinfogp.cnb.csic.es/tools/venny/index.html. Proteins with a region-specific distribution pattern (i.e., with zero spectral counts in one or more region) were grouped into the three classes "single region present," "single region absent," and "two-region present" (Table 2). For proteins that were present in all regions, five major patterns of distribution were identified that were based on the gradient starting from R1 to R4, such as "decreasing," "increasing," "R1-lowest," "R2-highest," and "R3highest" (Table 1). Proteins that were not present in all regions were grouped into three classes: "single region present," "single region absent," and "two regions present/absent" (Table 2).

\section{RESULTS AND DISCUSSION SPATIAL DISTRIBUTION OF RELATIVE ELONGATION RATE IN THE PRIMARY ROOT GROWTH ZONE}

Kinematic analysis showed that the primary root growth zone encompassed the apical $12 \mathrm{~mm}$ (Figure 1A). The relative elongation rate increased as the cells were displaced away from the

\footnotetext{
${ }^{1}$ http://www.thegpm.org

${ }^{2}$ http://www.ncbi.nlm.nih.gov/protein
} 


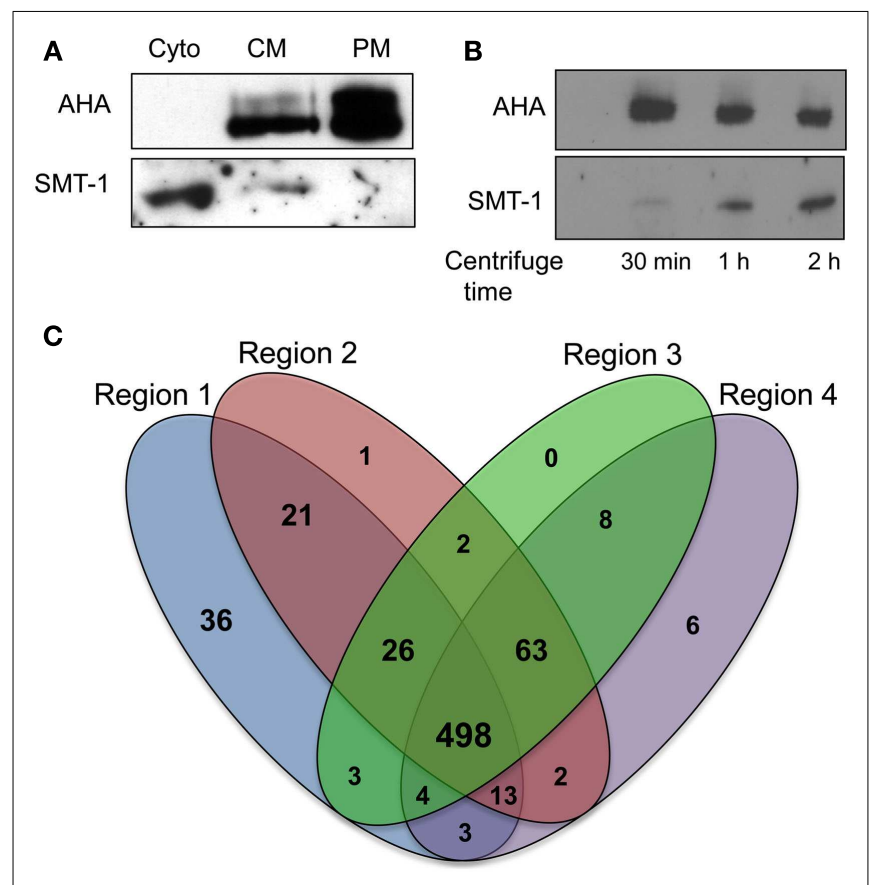

FIGURE 2 |Application of plasma membrane enrichment strategy to analysis of maize primary roots. (A) Proteins from steps of the enrichment procedure were analyzed by immunoblotting with organelle specific markers (Cyto, cytosolic fraction; CM, crude microsomal fraction; PM, plasma membrane-enriched fraction). Equal amounts of proteins from each fraction were analyzed with antibodies specific for a plasma membrane $\mathrm{H}^{+}$-ATPase (AHA) or an endoplasmic reticulum integral membrane sterol methyltransferase (SMT-1). (B) Increasing time of ultracentrifugation increases ER proteins in crude microsomal pellets. Proteins were prepared for immunoblot analysis as for $(\mathbf{A})$, except that the ultracentrifugation at $100,000 \times \mathrm{g}$ was performed for $30 \mathrm{~min}, 1 \mathrm{~h}$, or $2 \mathrm{~h}$. Equal amounts of proteins from each crude microsomal fraction were analyzed with antibodies specific for $\mathrm{PM} \mathrm{H}^{+}$-ATPases (AHA) or an endoplasmic reticulum integral membrane sterol methyltransferase (SMT-1). (C) Four-way Venn diagram showing number of proteins identified from the four regions (created using algorithm from: http://bioinfogp.cnb.csic.es/tools/venny/index.html). the ER membrane marker SMT-1 (integral ER sterol methyltransferase). Equal amounts of protein from the soluble protein fraction (obtained from the first ultracentrifugation step), crude microsomal fraction, and PM-enriched fraction were separated by SDS-PAGE and blotted with antibodies of AHA1 and SMT-1 (Figure 2A). Comparisons of the CM and PM fractions clearly showed an increase in signal corresponding to AHA proteins in the putative PM-enriched fraction while the abundance of SMT-1 decreased. The presence of the SMT-1 marker in the soluble fraction was unexpected, but we speculated that perhaps the relatively short duration $(30 \mathrm{~min})$ of ultracentrifugation was not sufficient to pellet all of the ER fraction. Thus, we investigated if increasing the duration of ultracentrifugation affected the representation of SMT-1 in the microsomal pellet. Indeed, we found that increasing the duration of ultracentrifugation to longer than $30 \mathrm{~min}$ increased the proportion of SMT-1 relative to AHA in the microsomal fraction (Figure 2B). Therefore, the $30 \mathrm{~min}$ ultracentrifugation was used in all subsequent experiments to decrease ER contamination, thereby increasing the proportion of PM proteins in the sample. These results show that the PM enrichment strategy using Brij-58 detergent contained the highest levels of AHA1 and lowest levels of SMT-1, indicating that the PM fraction was enriched for PM proteins while depleting proteins from the ER. Therefore, the simplified PM enrichment protocol previously described for use in Arabidopsis suspension cell cultures (Zhang and Peck, 2011) also is applicable to studies in unrelated tissues such as the maize primary root.

Equal amounts of the PM-enriched protein fractions from the four contiguous regions in the root growth zone were loaded and separated by 1D SDS-PAGE. After separation of samples from a biological replicate, gel slices were excised and digested with trypsin, and the resultant peptide fractions were analyzed by LS$\mathrm{MS} / \mathrm{MS}$ analysis for comparisons of PM-enriched proteomes in the different regions of the growth zone (Figure 1B; summary of all raw and processed LC-MS/MS data from each biological replicate is found in Table S1 in Supplementary Material).

\section{PROTEIN DISTRIBUTION PATTERNS}

For analysis of quantitative protein distributions, proteins were considered to be reproducibly identified if they were found in two of the three biological replicates. Comparisons of this subset of reproducible proteins showed that there was a $72 \%(498 / 686)$ overlap between proteins identified from the four contiguous root regions (Figure 2B). R1, which contained the meristem and zone of accelerating elongation rate, had the most unique proteins compared to the other regions (36 in R1 versus 1 in R2, 0 in R3, and 6 in R4). Contiguous regions (R1-3 or R2-4) were more similar than non-contiguous regions ( $\mathrm{R} 1$ and $\mathrm{R} 4$ ), indicating that the proteomes reflect the developmental gradient of root elongation.

We next analyzed the distribution of proteins in terms of relative abundance throughout the different regions. Of the 686 proteins, $83 \%$ (574) did not show any specific pattern of distribution, whereas 6\% (43) showed region-distributed patterns (Table 1) and $11 \%$ (74) were present in only one or two regions (Table 2 ). The protein distribution patterns between the four different regions were grouped into several categories (Table 1). For example, when 


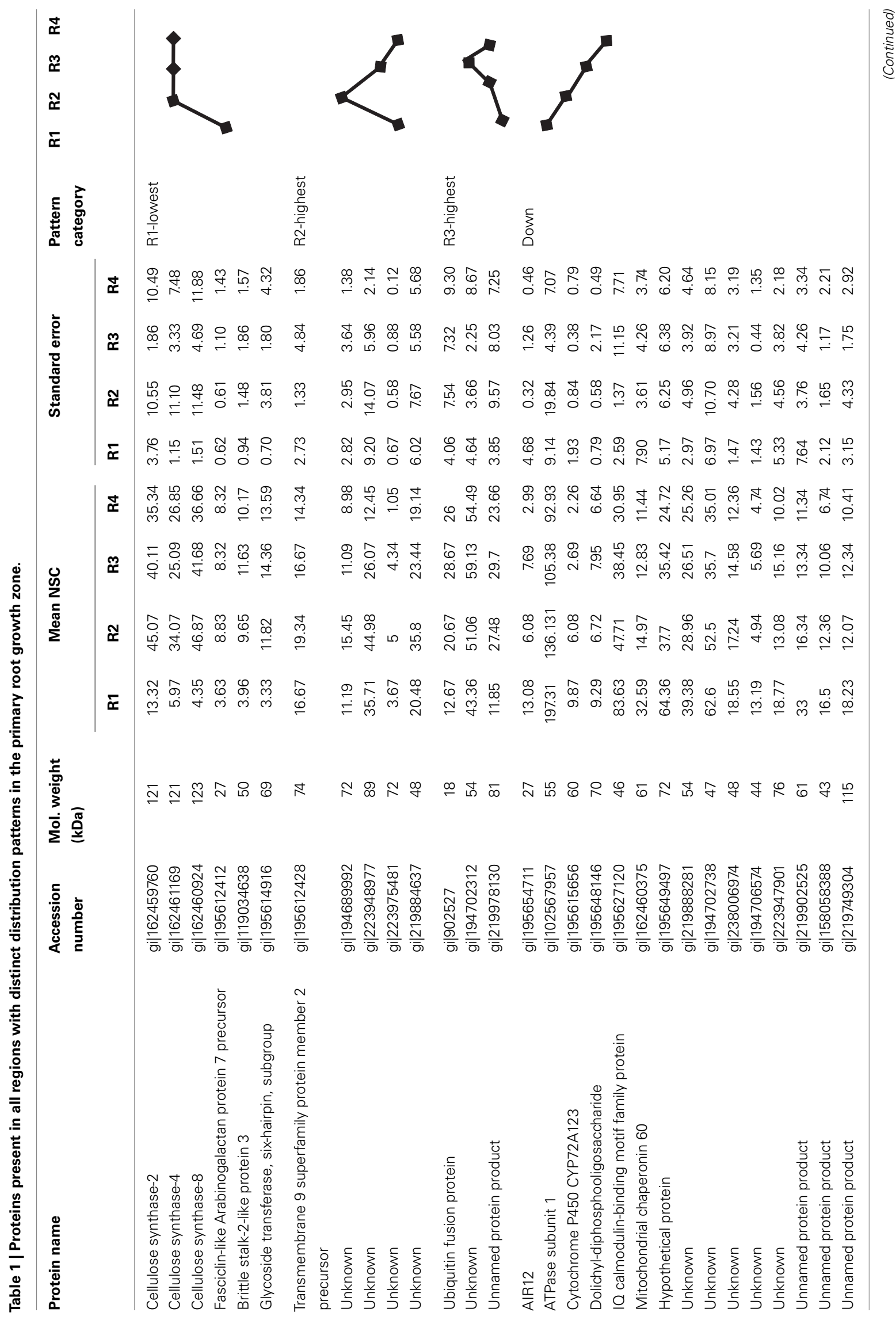




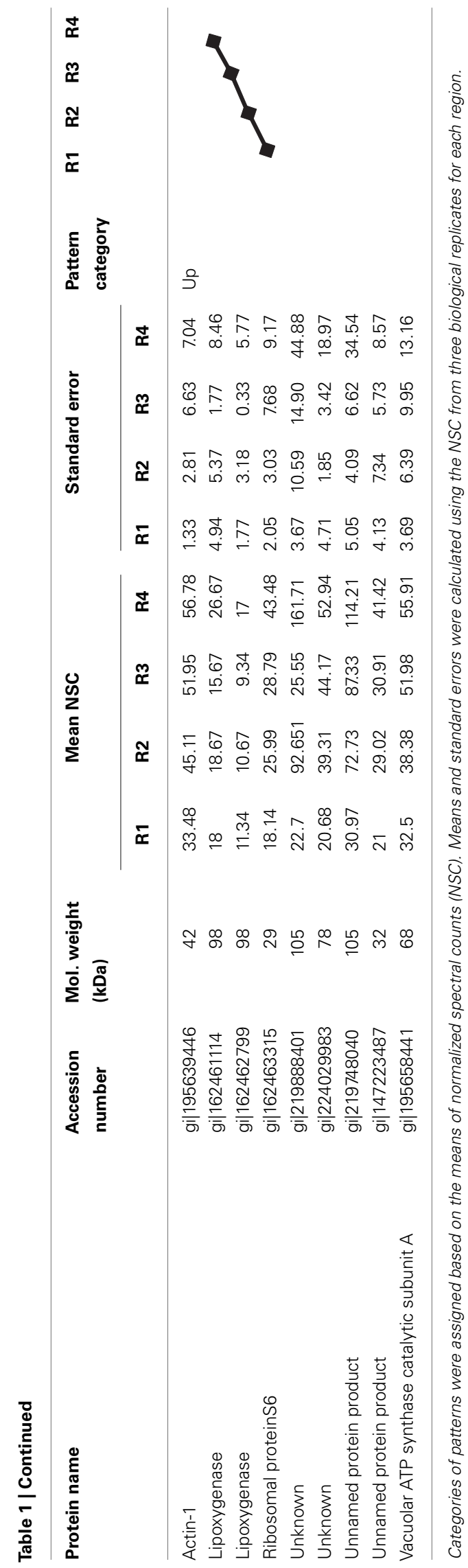

a protein showed lowest expression in R1 and similar levels in $\mathrm{R} 2-4$, it was grouped in the category "R1-lowest." In contrast, if a protein showed highest expression in R1 and decreasing abundance thereafter, it was categorized into the group "down" (see Table 1 for details). Because of the incomplete annotation of the maize genome, a large number of the proteins with defined distribution patterns are listed as "unknown." However, for some of the annotated proteins, the distribution pattern appears to be consistent with possible biological functions in the growing root, and a few of these examples are discussed below.

\section{REGION-SPECIFIC CHANGES IN AQUAPORIN PROFILES - ROLE IN WATER MOVEMENT}

The movement of water in plant tissues occurs by both an apoplastic pathway and a symplastic pathway (Steudle, 2000). The PM intrinsic proteins (PIPs), or aquaporins, are involved in symplastic movement of water across cellular membranes (Maurel and Chrispeels, 2001). Their relative contribution in water movement increases as tissues mature and develop apoplastic barriers such as suberized/lignified cell wall deposits, which reduce apoplastic water movement (Hachez et al., 2006). The results from the present study show a developmental gradient in the abundance of numerous aquaporin proteins (Figure 3A). The protein level of ZmPIP2-2 was lowest in $\mathrm{R} 1$ and increased thereafter, reaching a maximum in R4. ZmPIP2-3, 4 and ZmMIP proteins were not detected in $\mathrm{R} 1$, whereas there was a progressive increase in their abundance from R2 to R4. The increased aquaporin protein abundance in $\mathrm{R} 4$, which represented the maturation region beyond the growth zone (including suberization/lignification of the endodermis and development of the casparian strip), is likely involved in increased symplastic water transport. The abundance pattern of aquaporins observed in this study is similar to the aquaporin abundance patterns observed previously using immunoblot analyses in maize primary roots by Hachez et al. (2006). Therefore, our quantitative PM proteomic comparison is consistent with known spatial gradients of PM proteins, supporting the validity of this strategy.

\section{SPATIAL DISTRIBUTION OF AIR12 PROTEINS - POTENTIAL ROLE IN REDOX SIGNALING}

Two apparent maize orthologs of Arabidopsis thaliana AIR12 (for auxin induced in root cultures) were identified in all four regions of the root (Figure 3B). One of the ZmAIR12 proteins (gi 195608915) was ubiquitously distributed across all four regions, whereas another ZmAIR12 (gi 195654711) was more abundant in R1 compared to R2-4. An ortholog of AtAIR12 in soybean was recently identified as the major PM-localized b-type cytochrome that is fully reduced by ascorbate and fully oxidized by monodehydroascorbate radicals (Preger et al., 2009). The AtAIR12 and GmAIR12 proteins were found to be highly glycosylated and contained a glycosylphosphatidylinositol-anchor that positioned the proteins on the external side of the PM in vivo (Borner et al., 2003; Preger et al., 2005, 2009). AIR12 is physically associated with other redox signaling proteins and is suggested to be a link between the apoplast and cytoplasm in redox signaling (Lefebvre et al., 2007; Preger et al., 2009). Therefore, higher levels of ZmAIR12 (gi 195654711) in R1 of the maize primary root may 
Table 2 | Proteins only present in specific regions in the primary root growth zone.

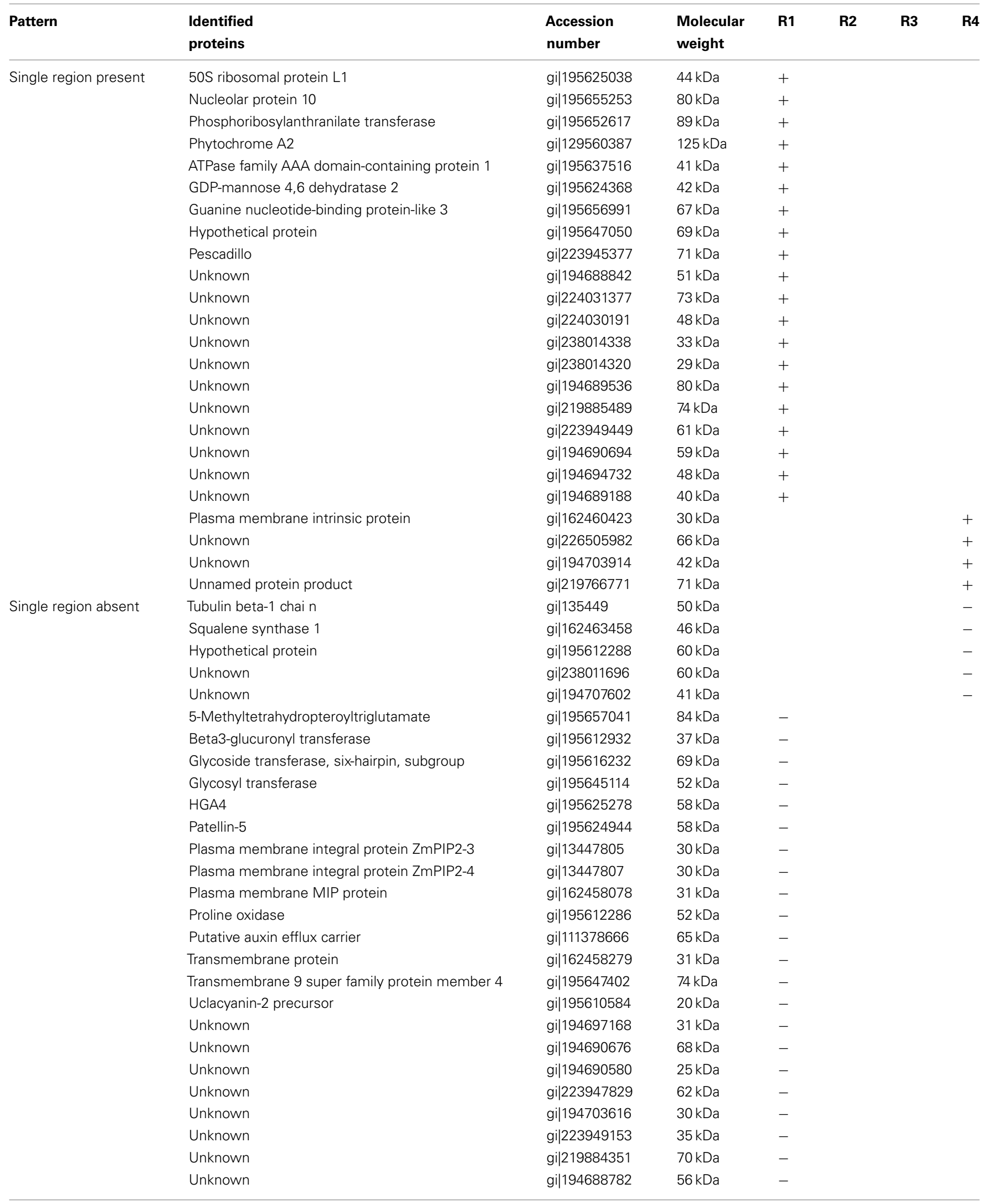


Table 2 | Continued

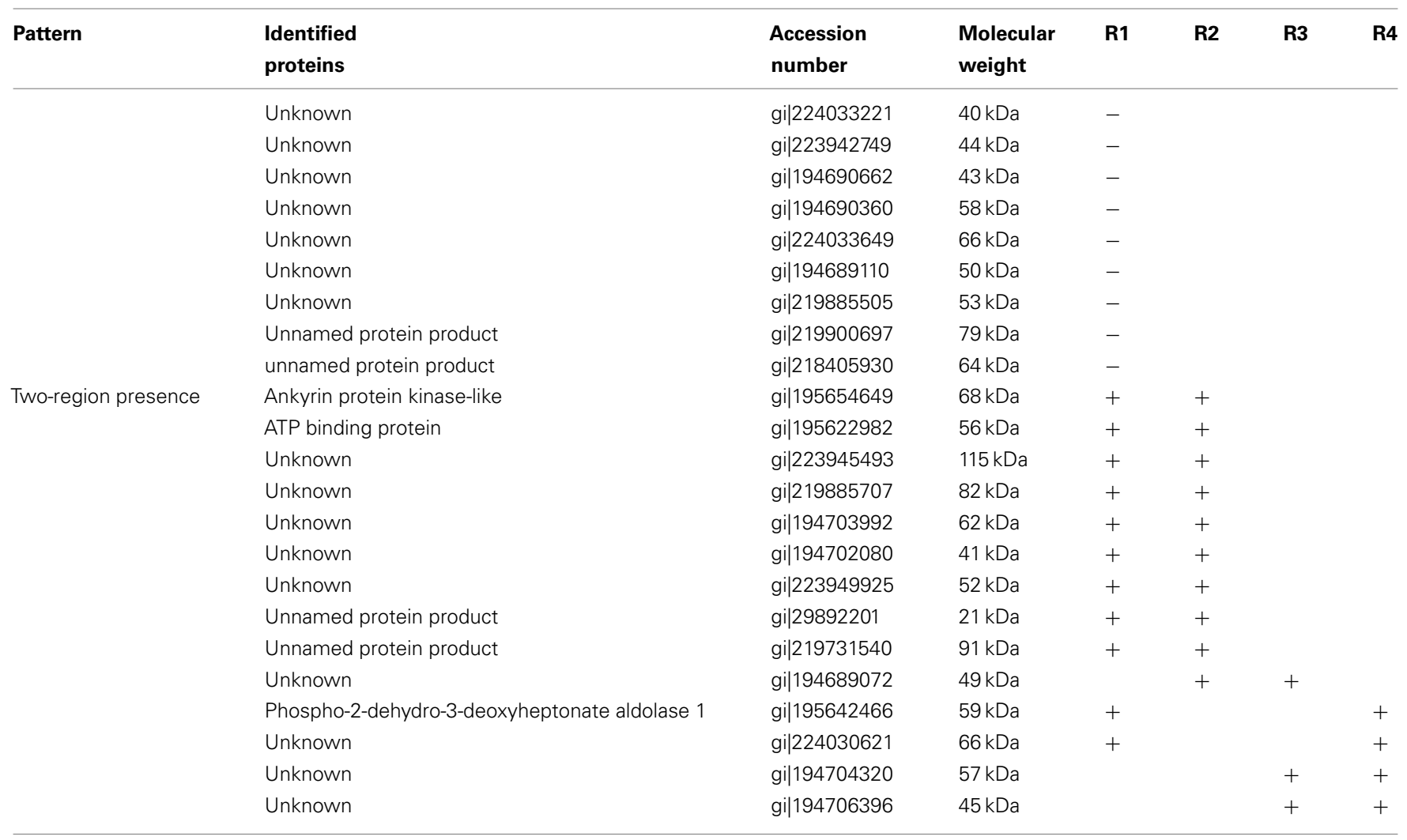

Region-specific patterns were assigned based on the means of normalized spectral count (NSC). Means and standard errors were calculated using the NSC from three biological replicates for each region.

indicate increased redox signaling, which would be consistent with increased apoplastic superoxide production in this region that has been suggested to play a role in cell wall loosening activities (Liszkay et al., 2004). In addition, increased superoxide production in the apical region of primary roots of Arabidopsis was suggested to be involved in regulating meristem size (Tsukagoshi et al., 2010). If ZmAIR12 activity is involved in regulating cell expansion, it will be interesting to understand how this process is regulated as one member of the protein family is uniformly distributed in all regions whereas another shows region-distributed accumulation.

\section{SPATIAL DISTRIBUTION OF CELL WALL BIOSYNTHESIS RELATED PROTEINS \\ Cellulose synthases}

Cellulose, the main constituent of plant cell walls, is composed of parallel unbranched glucan chains referred to as cellulose microfibrils (Anderson et al., 2010). These microfibrils are synthesized by large multimeric complexes of cellulose synthase proteins at the PM (Somerville, 2006). As cells expand, there is increased deposition of cellulose synthase complexes at the PM, and these complexes in turn deposit cellulose necessary for maintaining rigidity and directional growth of the cells (Baskin, 2005). Several cellulose synthases were identified in the PM-enriched fraction from the different regions of the maize primary root (Table 1). The abundance of cellulose synthases was lowest in R1, increased in R2, and remained high in R3-4 (Figure 4A). Because the integrated expansion of the cells in the maize primary root (as determined by the area under the relative elongation rate curve) is maximal in R2-3, the increased abundance of cellulose synthases in these regions is consistent with increased cell wall deposition in the elongating cells. As R4 corresponds to the region of maturation and secondary cell wall synthesis (Figure 1A), an increased abundance of cellulose synthases in this region is consistent with increased cell wall maturation (Figure 4A).

\section{Glycosyltransferases}

Several glycosyltransferases were differentially distributed throughout the regions of the root (Figure 4B). Glycosyltransferases are enzymes that transfer a sugar moiety from activated donor to acceptor molecules forming glycosidic bonds (Zhong and Ye, 2003; Lim and Bowles, 2004). Plant glycosyltransferases are involved in biosynthesis of several cell wall components such as polysaccharides, hemicelluloses, and pectins, and these enzymes may also be involved in transferring sugar molecules to proteins, hormones, and secondary metabolites (Zhong and Ye, 2003; Liepman et al., 2010). Therefore, the increased abundance of various glycosyltransferases particularly in the regions of maximal cell expansion (R2-3; Figure 1A) and secondary cell wall formation (R4) indicates that the glycosyltransferases identified in this study may be involved in cell wall synthesis (Figure 4B). Although some studies have suggested that glycosyltransferases are associated 

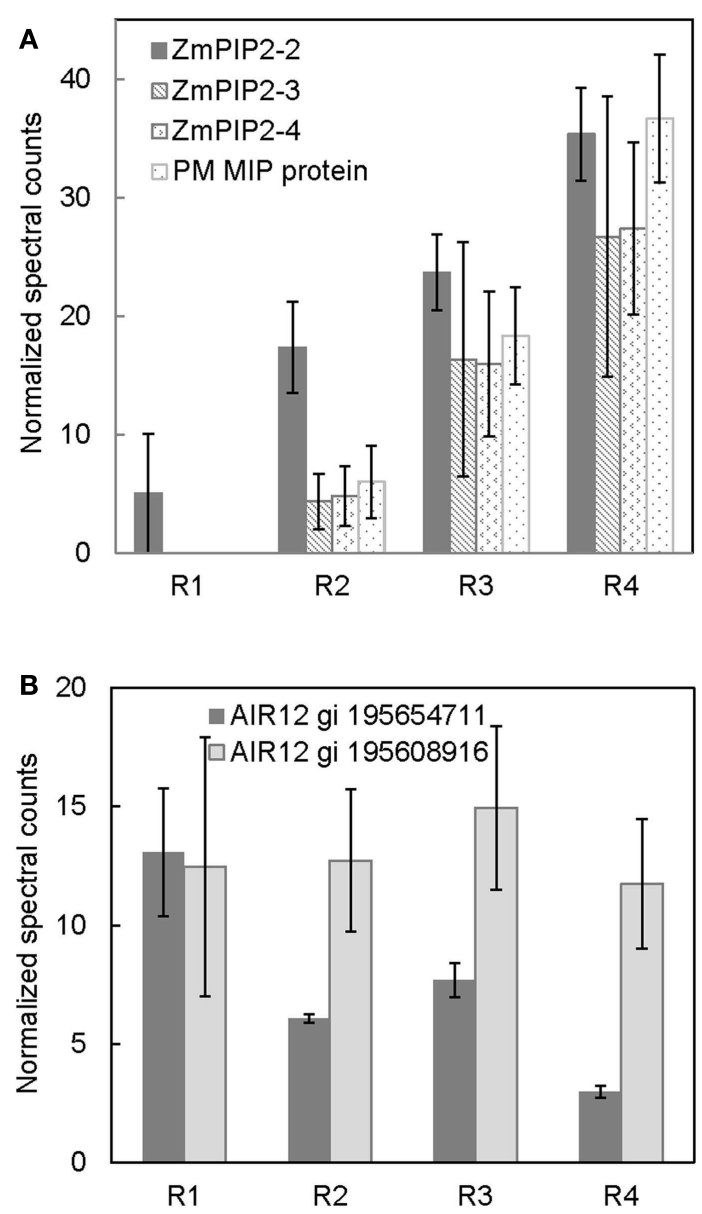

FIGURE 3 | Spatial distribution of (A) aquaporin protein abundances, and (B) ZmAIR12 protein abundances in R1-4 of the maize primary root harvested $48 \mathrm{~h}$ after transplanting to well-watered conditions. Data are means $\pm S E$ of normalized spectral counts from three replicate experiments.

with endomembranes (Keegstra, 2010), the localization of cellulose synthases, a major family of glycosyltransferases, at the PM suggests that glycosyltransferases can be associated with the PM (Scheible and Pauly, 2004; Somerville, 2006). Additionally, a recent study of PM proteomics in poplar in which the PM fraction was obtained from two-phase partitioning of microsomal membranes identified several glycosyltransferases (Nilsson et al., 2010). Therefore, it is likely that different classes of glycosyltransferases are localized to different compartments dependent on their function(s).

\section{Brittlestalk-2-like protein 3 and fasciclin-like arabinogalactan proteins}

The orientation of microfibrils is known to regulate cell shape. In isotropic expansion, the microfibrils are oriented in all directions, whereas in anisotropic expansion they are oriented perpendicular to the direction of expansion (Baskin, 2005). Although expansion is anisotropic in the root growth zone, the degree of anisotropy increases as the cells move away from the root apex
(Liang et al., 1997; Baskin et al., 2004). These changes potentially involve changes in cellulose microfibril orientation and patterning. Several studies have shown that the cellulose microfibril orientation can be modified by PM-localized proteins such as COBRA and fasciclin-like arabinogalactan proteins in Arabidopsis and an ortholog of COBRA in maize, brittlestalk-2 (Roudier et al., 2005; Ching et al., 2006; MacMillan et al., 2010).

Brittlestalk-2 (bk2) was identified in a screen for maize mutants defective in cellulose biosynthesis; the mutant stalks had reduced mechanical strength (Ching et al., 2006). Analysis of the brittle phenotype found that disruption in the $b k 2$ gene interferes with the pattern of cellulose microfibril deposition, which leads to reduced cellulose and increased lignin in the $b k 2$ mutant shoot tissues (Ching et al., 2006; Sindhu et al., 2007). In Arabidopsis, the ortholog of $b k 2, C O B R A$, encodes a GPI-anchored PMlocalized protein that is suggested to regulate cellulose microfibril deposition and anisotropic expansion in both primary root and hypocotyl tissues (Roudier et al., 2005). The protein abundance pattern of brittlestalk-2-like protein (Figure 4C) is similar to the mRNA expression pattern of COBRA in the primary root (Roudier et al., 2005), suggesting that brittlestalk-2-like protein may be involved in cellulose microfibril patterning and anisotropic expansion in the maize primary root.

Similarly, fasciclin-like arabinogalactan proteins are suggested to be involved in cellulose microfibril orientation and secondary cell wall synthesis in Arabidopsis and Eucalyptus (MacMillan et al., 2010). These proteins belong to a large protein family containing the cell adhesion fasciclin domain, which is also conserved in cell adhesion proteins in bacteria, algae, fungi, and animals (Johnson et al., 2003). In plants, the fasciclin-like arabinogalactan proteins are suggested to be PM-localized either with or without a GPI-anchor (Borner et al., 2003; Johnson et al., 2003; Lefebvre et al., 2007). However, the functions of the various fasciclin-like arabinogalactan proteins in plants are still largely unknown. Recent analysis revealed that mutations in two stemspecific fasciclin-like-arabinogalactan proteins lead to altered cellulose deposition and reduced stem stiffness in Arabidopsis stems (MacMillan et al., 2010). Thus, the increased accumulation of fasciclin-like-arabinogalactan protein in R2-4 (Figure 4D) hints at a role for this protein in modification of cellulose microfibril deposition.

\section{CONCLUSION}

The results in the present study demonstrate that the simplified PM enrichment method previously shown to work in Arabidopsis also can be used to characterize the developmental distribution of PM proteins in the maize primary root. Therefore, it appears that this technical strategy may be more broadly applicable to PM protein studies in diverse plant species. In addition, we found that shorter durations of ultracentrifugation decrease the representation of the ER marker, SMT-1, in the microsomal fraction. We hypothesize that this difference is caused because of the differences in buoyant densities of PM vs. ER-containing vesicles in maize root extracts. However, it should be noted that this method does not replace more stringent, but challenging, methods such as two-phase partitioning if the goal of the study is to more conclusively demonstrate that a protein specifically localizes to the PM. 

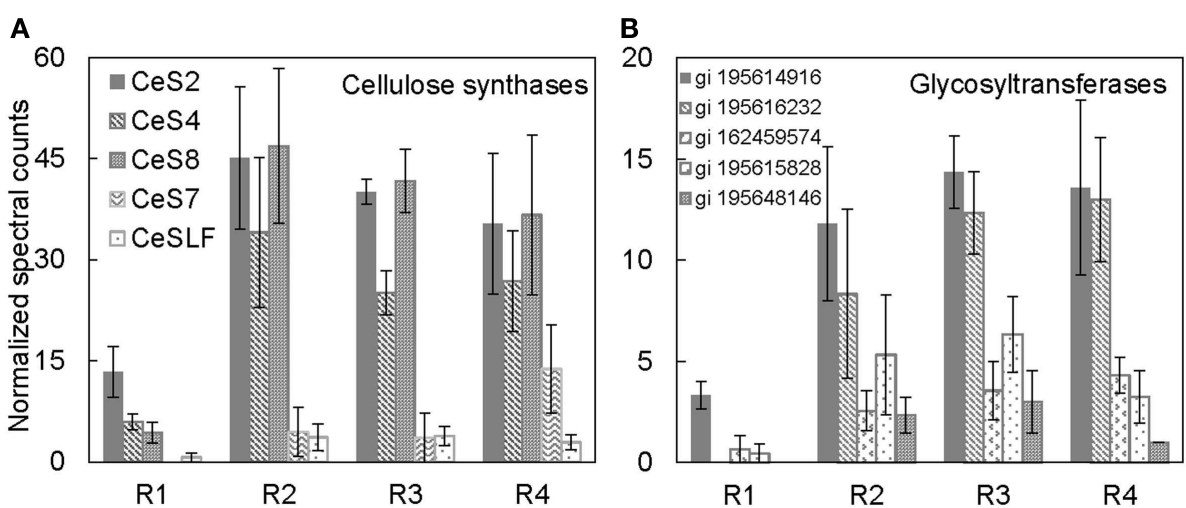

C

D
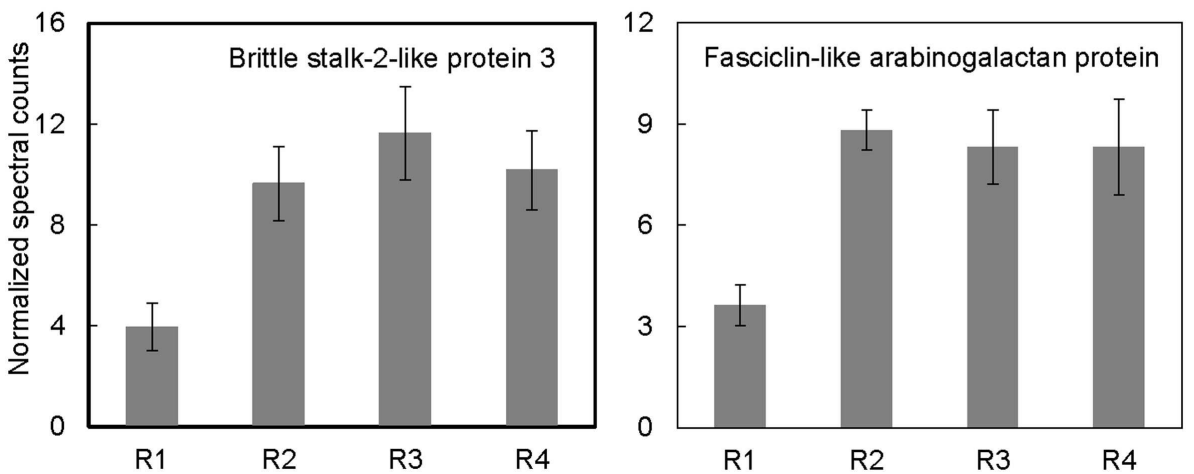

FIGURE 4 | Spatial distribution patterns of protein abundances for (A) cellulose synthases, (B) glycosyltransferases, (C) brittle stalk-2-like protein 3, and (D) fasciclin-like arabinogalactan proteins in R1-4 of the

maize primary root harvested $48 \mathrm{~h}$ after transplanting to well-watered conditions. Data are means \pm SE of normalized spectral counts from three replicate experiments.

Rather, the present method serves as a simple and robust method to increase the representation of PM proteins in proteomic studies.

Of the proteins showing defined developmental distribution patterns in the primary root of maize, a number of them, such as the aquaporins and cellulose synthases, appear logical in relation to their roles in cell expansion. Therefore, other proteins of unknown function such as the glycosyltransferases and the fasciclin-like arabinogalactans serve as candidates for involvement in growth regulation. Of course, further characterization studies are needed to determine the functional significance of their differential distribution in the growth zone of the maize primary root.

\section{REFERENCES}

Albertsson, P. A., Cajarville, A., Brooks, D. E., and Tjerneld, F. (1987). Partition of proteins in aqueous polymer two-phase systems and the effect of molecular weight of the polymer. Biochim. Biophys. Acta 926, 87-93.

Anderson, C. T., Carroll, A., Akhmetova, L., and Somerville, C. (2010). Real-time imaging of cellulose reorientation during cell wall expansion in Arabidopsis roots. Plant Physiol. 152, 787-796.

Baskin, T. I. (2005). Anisotropic expansion of the plant cell wall. Annu. Rev. Cell Dev. Biol. 21, 203-222.
Baskin, T. I., Beemster, G. T. S, JudyMarch, J. E., and Marga, F. (2004). Disorganization of cortical microtubules stimulates tangential expansion and reduces the uniformity of cellulose microfibril alignment among cells in the root of Arabidopsis thaliana. Plant Physiol. 135, 2279-2290.

Beemster, G. T., and Baskin, T. I. (1998). Analysis of cell division and elongation underlying the developmental acceleration of root growth in Arabidopsis thaliana. Plant Physiol. 116, 1515-1526.

Bernstein, N., Lauchli, A., and Silk, W. K. (1993). Kinematics and dynamics

\section{ACKNOWLEDGMENTS}

We acknowledge Dr. Jeffrey Anderson for his useful suggestions and discussions about this work.

\section{SUPPLEMENTARY MATERIAL}

The Supplementary Material for this article can be found online at http://www.frontiersin.org/Plant_Proteomics/10.3389/ fpls.2013.00033/abstract

Table S1 | Complete list of all raw and normalized spectral counts for proteins identified in this study.

of sorghum (Sorghum bicolor L.) leaf development at various $\mathrm{Na} / \mathrm{Ca}$ salinities. Plant Physiol. 103, 1107-1114.

Borner, G. H. H., Lilley, K. S., Stevens, T. J., and Dupree, P. (2003). Identification of glycosylphosphatidylinositol-

anchored proteins in Arabidopsis. A proteomic and genomic analysis. Plant Physiol. 132, 568-577.

Brady, S. M., David, A., Orlando, D. A., Lee, J., Wang, J. Y., Koch, J., et al. (2005). A high-resolution root spatiotemporal map reveals dominant expression patterns. Science 318, 801-806.
Ching, A., Dhugga, K. S., Appenzeller, L., Meeley, R., Bourett, T. M., Howard, R. J., et al. (2006). Brittle stalk2 encodes a putative glycosylphosphatidylinositolanchored protein that affects mechanical strength of maize tissues by altering the composition and structure of secondary cell walls. Planta 224, 1174-1184.

Cosgrove, D. J. (1989). Characterization of long-term extension of isolated cell walls from growing cucumber hypocotyls. Planta 177, 121-130.

Endler, A., and Persson, S. (2011). Cellulose synthases and synthesis in Arabidopsis. Mol. Plant 4, 199-211. 
Ephritikhine, G., Ferro, M., and Rolland, N. (2004). Plant membrane proteomics. Plant Physiol. Biochem. 42, 943-962.

Erickson, R. O. (1961). Probability of division of cells in the epidermis of the Phleum root. Am. J. Bot. 48, 268-274.

Erickson, R. O., and Silk, W. K. (1979). The kinematics of plant growth. Sci. Am. 242, 134-151.

Hachez, C., Moshelion, M., Zelazny, E., Cavez, D., and Chaumont, F. (2006). Localization and quantification of plasma membrane aquaporin expression in maize primary root: a clue to understanding their role as cellular plumbers. Plant Mol. Biol. 62, 305-323.

Johnson, K. L., Jones, B. J., Bacic, A., and Schultz, C. J. (2003). The fasciclinlike arabinogalactan proteins of Arabidopsis. A multigene family of putative cell adhesion molecules. Plant Physiol. 133, 1911-1925.

Keegstra, K. (2010). Plant cell walls. Plant Physiol. 154, 483-486.

Keller, A., Nesvizhskii, A. I., Kolker, E., and Aebersold, R. (2002). Empirical statistical model to estimate the accuracy of peptide identifications made by MS/MS and database search. Anal. Chem. 74, 5383-5392.

Kiegle, E., Gilliham, M., Haseloff, J., and Tester, M. (2000). Hyperpolarization-activated calcium currents found only in cells from the elongation zone of Arabidopsis thaliana roots. Plant J. 21, 225-229.

Komatsu, S. (2008). Plasma membrane proteome in Arabidopsis and rice. Proteomics 8, 4137-4145

Lefebvre, B., Furt, F., Hartmann, M. A., Michaelson, L. V., Carde, J. P., Sargueil-Boiron, F., et al. (2007). Characterization of lipid rafts from Medicago truncatula root plasma membranes: a proteomic study reveals the presence of a raftassociated redox system. Plant Physiol. 144, 402-418.

Liang, B. M., Sharp, R. E., and Baskin, T. I. (1997). Regulation of growth anisotropy in wellwatered and water-stressed maize roots. I. Spatial distribution of longitudinal, radial and tangential expansion rates. Plant Physiol. 115, 101-111.

Liepman, A. H., Wightman, R., Geshi, N., Turner, S. R., and Scheller, H. V. (2010). Arabidopsis-a powerful model system for plant cell wall research. Plant J. 61, 1107-1121.

Lim, E. K., and Bowles, D. J. (2004). A class of plant glycosyltransferases involved in cellular homeostasis. EMBO J. 23, 2915-2922.

Liszkay, A., van der Zalm, E., and Schopfer, P. (2004). Production of reactive oxygen intermediates $\left(\mathrm{O}_{2}{ }^{-}\right.$, $\mathrm{H}_{2} \mathrm{O}_{2}$, and $\mathrm{OH}$ ) by maize roots and their role in wall loosening and elongation growth. Plant Physiol. 136, 3114-3123.

MacAdam, J. W., Sharp, R. E., and Nelson, C. J. (1992). Peroxidase activity in the leaf elongation zone of tall fescue. Plant Physiol. 99, 879-885.

MacMillan, C. P., Mansfield, S. D., Stachurski, Z. H., Evans, R., and Southerton, S. G. (2010). Fasciclinlike arabinogalactan proteins: specialization for stem biomechanics and cell wall architecture in Arabidopsis and Eucalyptus. Plant J. 62, 689-703.

Maurel, C., and Chrispeels, M. J. (2001). Aquaporins. A molecular entry into plant water relations. Plant Physiol. 125, 135-138.

Morel, J., Claverol, S., Mongrand, S., Furt, F., Fromentin, J., Bessoule, J. J., et al. (2006). Proteomics of plant detergent-resistant membranes. Mol. Cell Proteomics 5, 1396-1411.

Mulkey, T. J., and Evans, M. L. (1980). Geotropism in corn roots: evidence for its mediation by differential acid efflux. Science 212, 70-71.

Nesvizhskii, A. I., Keller, A., Kolker, E., and Aebersold, R. (2003). A statistical model for identifying proteins by tandem mass spectrometry. Anal. Chem. 75, 4646-4658.

Neuhoff, V., Stamm, R., and Eibl, H. (1985). Clear background and highly sensitive protein staining with Coomassie Blue dyes in polyacrylamide gels: a systematic analysis. Electrophoresis 6, 427-448.

Nilsson, R., Bernfur, K., Gustavsson, N., Bygdell, J., Wingsle, G., and Larsson, C. (2010). Proteomics of plasma membranes from poplar trees reveals tissue distribution of transporters, receptors, and proteins in cell wall formation. Mol. Cell Proteomics 9, 368-387.

Peters, W. S., and Bernstein, N. (1997). The determination of relative elemental growth rate profiles from segmental growth rates. Plant Physiol. 113, 1395-1404.

Pilet, P. E., Versel, J. M., and Mayor, G. (1983). Growth distribution and surface $\mathrm{pH}$ patterns along maize roots. Planta 158, 398-402.

Preger, V., Scagliarini, S., Pupillo, P., and Trost, P. (2005). Identification of an ascorbate-dependent cytochrome b of the tonoplast membrane sharing biochemical features with members of the cytochrome b561 family. Planta 220, 365-375.

Preger, V., Tango, N., Marchand, C., Lemaire, S. D., Carbonera, D., Valentin, M. D., et al. (2009). Auxinresponsive genes AIR12 code for a new family of plasma membrane btype cytochromes specific to flowering plants. Plant Physiol. 150, 606-620.

Roudier, F., Fernandez, A. G., Fujita, M., Himmelspach, R., Borner, G. H. H., Schindelman, G., et al. (2005). COBRA, an Arabidopsis extracellular glycosyl-phosphatidyl inositolanchored protein, specifically controls highly anisotropic expansion through its involvement in cellulose microfibril orientation. Plant Cell 17, 1749-1763.

Saab, I. N., Sharp, R. E., Pritchard, J. and Voetberg, G. S. (1990). Increased endogenous abscisic acid maintains primary root growth and inhibits shoot growth of maize seedlings at low water potentials. Plant Physiol. 93, 1329-1336.

Scheible, W. R., and Pauly, M. (2004). Glycosyltransferases and cell wall biosynthesis: novel players and insights. Curr. Opin. Plant Biol. 7, 285-295.

Sharp, R. E., Hsiao, T. C., and Silk, W. K. (1990). Growth of the maize primary root at low water potentials. II. Role of growth and deposition of hexose and potassium in osmotic adjustment. Plant Physiol. 93, 1337-1346.

Sharp, R. E., Poroyko, V., Hejlek, L. G., Spollen, W. G., Springer, G. K., and Bohnert, H. J., et al. (2004). Root growth maintenance during water deficits: physiology to functional genomics. J. Exp. Bot. 55 2343-2351.

Silk, W. K., Lord, E. M., and Eckard, K. J. (1989). Growth patterns inferred from anatomical records. Plant Physiol. 90, 708-713.

Sindhu, A., Langewisch, T., Olek, A. Multani, D. S., McCann, M. C., Vermerris, W., et al. (2007). Maize Brittle stalk2 encodes a COBRA-like protein expressed in early organ development but required for tissue flexibility at maturity. Plant Physiol. 145 1444-1459.

Somerville, C. (2006). Cellulose synthesis in higher plants. Annu. Rev. Cell Dev. Biol. 22, 53-78.

Steudle, E. (2000). Water uptake by roots: effects of water deficit. J. Exp. Bot. 51, 1531-1542.

Tsukagoshi, H., Busch, W., and Benfey, P. N. (2010). Transcriptional regulation of ROS controls transition from proliferation to differentiation in the root. Cell 143 , 606-616.

Wightman, R., and Turner, S. (2010). Trafficking of the plant cellulose synthase complex. Plant Physiol. 153, 427-432.

Wolters, H., and Jurgens, G. (2009). Survival of the flexible: hormonal growth control and adaptation in plant development. Nat. Rev. Genet. 10, 305-317.

Yamaguchi, M., and Sharp, R. E. (2010). Complexity and coordination of root growth at low water potentials: recent advances from transcriptomic and proteomic analyses. Plant Cell Environ. 33, 590-603.

Yamaguchi, M., Valliyodan, B., Zhang, J., LeNoble, M. E., Yu, O., Rogers, E. E. et al. (2010). Regulation of growth response to water stress in the soybean primary root. I. Proteomic analysis reveals region-specific regulation of phenylpropanoid metabolism and control of free iron in the elongation zone. Plant Cell Environ. 33, 223-243.

Zhang, Z., and Peck, S. C. (2011). Simplified enrichment of plasma membrane proteins for proteomic analyses in Arabidopsis thaliana. Proteomics 11, 1780-1788.

Zhong, R., and Ye, Z. (2003). Unraveling the functions of glycosyltransferase family 47 in plants. Trends Plant Sci. 12, 565-568.

Conflict of Interest Statement: The authors declare that the research was conducted in the absence of any commercial or financial relationships that could be construed as a potential conflict of interest.

Received: 31 October 2012; accepted: 10 February 2013; published online: 06 March 2013.

Citation: Zhang Z, Voothuluru P, Yamaguchi $M$, Sharp RE and Peck SC (2013) Developmental distribution of the plasma membrane-enriched proteome in the maize primary root growth zone. Front. Plant Sci. 4:33. doi: 10.3389/fpls.2013.00033

This article was submitted to Frontiers in Plant Proteomics, a specialty of Frontiers in Plant Science.

Copyright (c) 2013 Zhang, Voothuluru, Yamaguchi, Sharp and Peck. This is an open-access article distributed under the terms of the Creative Commons Attribution License, which permits use, distribution and reproduction in other forums, provided the original authors and source are credited and subject to any copyright notices concerning any third-party graphics etc. 